\title{
Nível de conhecimento e desempenho dos acadêmicos de enfermagem quanto à técnica correta da punção venosa periférica
}

Daiane Pinto de Almeida*, Mariana Ellen Teixeira Rodrigues*, Paola de Lima Cruz*, Josiane Lima da Silva**

*Acadêmica do curso de Enfermagem da Fundação Presidente Antônio Carlos - FUPAC/Ubá, **Enfermeira, Especialista em Enfermagem do Trabalho e Docente do Curso de Enfermagem da Fundaçâo Presidente Antônio Carlos

\section{Resumo}

Introduçâo: A punção venosa periférica é definida como um procedimento que se caracteriza pela colocação de um dispositivo no interior do vaso venoso, podendo ou não ser fixado à pele, e que requer cuidados e controle periódico, em caso de sua permanência. Objetivo: Avaliar o nível de conhecimento e desempenho de acadêmicos de enfermagem no momento da punçáo venosa periférica em situação real de assistência. Material e métodos: Foram analisados 30 alunos do curso de graduaçáo em enfermagem da FUPAC/Ubá matriculados no $6^{\circ}$ e $8^{\circ}$ períodos no ano de 2010, entre 20 e 40 anos de idade e de ambos os sexos. Os instrumentos de análise foram um questionário e a observação direta da prática. Para análise dos dados utilizou-se a estatística descritiva com cálculo das médias, desvio padrão e porcentagem. Resultados: Permitiram identificar que os alunos do oitavo período assimilaram melhor o conteúdo da matéria de Semiologia e Semiotécnica I e que os do sexto período apresentaram maior insegurança na realização da punção venosa periférica. Observou-se que os alunos de ambos os períodos obtiveram desempenho satisfatório e erros semelhantes no desempenho técnico. Conclusão: Conclui-se que, cada vez mais, deve ser implementado ao curso de graduação um constante aperfeiçoamento dos alunos no que se diz respeito a punçáo venosa periférica e que os mesmo devem se sensibilizar da importância de prevenir erros, visto que, é um procedimento rotineiro para um profissional de enfermagem.

Palavras-chave: punção, cateter, Enfermagem.

\section{Abstract}

\section{Nursing student's level and performance concerning the right venipuncture technique}

Introduction: The venipuncture is defined as a procedure which involves the insertion of a device into the venous vessel, which may or not be attached to the skin and requires regular care and control in case of its stay. Objective: To assess the level of knowledge and performance of nursing students when performing venipuncture. Material and methods: We analyzed 30 students from undergraduate nursing FUPAC University/Ubá enrolled in the 6th and 8th periods in 2010, between 20 and 40 years old and both sexes. A questionnaire and direct observation of practice were the instruments of analysis. For data analysis we used descriptive statistics to calculate the mean, standard deviation and percentage. Results: The results showed that comparing the eighth grade students with the sixth, the former assimilated better the content of Semiology and Semiotics 
I disciplines and the sixth grade students felt much more insecure in performing venipuncture than the eighth grade. We observed that students in both grades had a satisfactory performance and similar mistakes in technical performance. Conclusion: We concluded that a continuous improvement regarding venipuncture procedure should be included in the undergraduate courses and that the students should be conscious of the importance of preventing mistakes, because it is a routine procedure to a nursing professional.

Key-words: puncture, catheter, Nursing.

\section{Resumen}

\section{Nivel de conocimiento y desempeño de académicos de enfermería con relación a la técnica correcta de punción venosa periférica}

Introducción: La punción venosa periférica se define como un procedimiento que se caracteriza por la inserción de un dispositivo en el interior del vaso venoso, que puede o no ser fijado en la piel, y que requiere cuidados y control periódico, en caso de su permanencia. Objetivo: Evaluar el nivel de conocimiento y desempeño de académicos de enfermería durante la realización de la técnica de acceso venoso periférico en la práctica del cuidado. Material e métodos: Fueron analizados 30 alumnos del Curso de Enfermería de la Universidad FUPAC- Ubá admitidos en el sexto y octavo periodo del ańo de 2010, de ambos sexos entre 20 y 40 anos. Los instrumentos de análisis fueron un cuestionario y la observación directa de la práctica. Para el análisis de datos se usaron la estadística descriptiva con cálculo de la media, desviación estándar y porcentaje. Resultados: Se ha identificado que los alumnos del octavo periodo asimilaron mejor el contenido de la disciplina de Semiología y Semiótica I y que los del sexto periodo se sintieron inseguros al realizar la punción venosa periférica. Se observó que los alumnos de ambos periodos tuvieron desempeño satisfactorio y errores semejantes en desempeño técnico. Conclusión: Se concluye que un constante perfeccionamiento de los alumnos con respecto a la punción venosa periférica debe ser implementado al curso de Enfermería para que los mismos se puedan concientizar de la importancia de prevenir errores, una vez que es un procedimiento de rutina del profesional de enfermería.

Palabras-clave: punción, catéter, Enfermería.

\section{Introdução}

A punção venosa periférica (PVP) é um procedimento que se caracteriza pela colocação de um dispositivo no interior do vaso venoso $[1,2]$, podendo ou não ser fixado à pele e que requer cuidados e controle periódico, em caso de sua permanência [1]. É indicada para a maioria dos pacientes hospitalizados, representando por vezes uma condição prioritária para o seu atendimento [3-5]. Suas principais finalidades incluem coleta de amostra de sangue, administração de medicamentos, acesso para infusão intravenosa, injeção de meio de contraste para exame radiológico e hemotransfusão $[2,6]$.

Inicialmente, o acesso vascular periférico era realizado com agulhas de aço inoxidável, as quais, embora apresentem menor risco de infecção, são rígidas, resultando na perda do acesso com facilidade [6] e maior risco de extravasamento, sendo indicadas apenas quando o tempo de infusão é curto [7]. Em 1945, foi introduzido o cateter venoso plástico, permitindo manutenção por tempo mais prolongado [6].
Concomitante ao avanço tecnológico da terapia intravenosa, a PVP [8], entre todas os procedimentos realizados pelos profissionais de enfermagem é umas das mais frequentes $[1,3,5]$, representando aproximadamente $85 \%$ delas [1], executadas por profissionais com diferentes níveis de formação ou habilitação, o que pode gerar variabilidade no desempenho [1,3]; exigindo competência técnica, destreza manual e domínio de fisiologia e anatomia [1-3,8-10]. Assim, fatores como habilidade prática, preparo do paciente, a escolha, obtençáo e manutenção do dispositivo e da veia adequada, administração de drogas e soluçóes [3,8,9], a documentação e avaliação do cuidado com o acesso intravascular devem ser considerados pelo enfermeiro como resultantes de uma reflexão para que o melhor cuidado seja prestado ao paciente $[1,3]$.

Os acessos vasculares são temporários ou provisórios [11] e são realizados principalmente em veias dos membros superiores [2,6,12]. Entretanto, as veias das mãos são tortuosas e instáveis e, por isso, devem ocupar lugar secundário de escolha, pois nelas há grande facilidade de se perder o aces- 
so, devido à instabilidade característica das veias nesse local [13].

Portanto, quando se pretende que haja de média a longa permanência da técnica, faz-se necessário buscar veias pouco sinuosas e calibrosas, situadas em locais que ofereçam estabilidade da punçáo como, por exemplo, antebraço e braço $[2,13]$. Por outro lado, se a punçáo venosa for utilizada para uma única injeção de medicamento, as veias da dobra do cotovelo (basílica, mediana e cefálica) são as mais indicadas, pois oferecem boa visualizaçáo e fácil acesso [13].

Pode-se afirmar que a PVP é um procedimento invasivo, considerando que o dispositivo provoca o rompimento da proteçáo natural da pele que, quando íntegra, representa importante barreira contra os microrganismos. Contudo é colonizada por microbiota própria, que numa punção, se não eliminada ou inativada por antissepsia rigorosa com álcool a 70\%, pode penetrar na corrente sanguínea e o paciente desenvolver infecçóes $[1,6]$, que pode ir desde uma simples ocorrência no local da punção até situaçóes mais graves $[1,11,13]$.

A flebite, a infiltração e o extravasamento são as complicaçóes mais frequentemente relacionadas ao uso de cateteres venosos periféricos (CVP), estáo relacionados a seu tempo de permanência $[2,6,8,14]$ e quando são deixados no mesmo local por um período superior a 72 horas [8], faz com que a colonização microbiana aumente. Caso haja sinais e sintomas de complicaçóes, a terapia deve ser suspensa imediatamente $[15,8]$.

Desta forma, o tempo de permanência do acesso venoso periférico deve ser rigorosamente controlado e devidamente registrado no prontuário do paciente, evitando que erros na contagem de tempo induzam complicaçóes evitáveis. Sendo assim, devem-se anotar no dispositivo de fixação da punção a data e hora do procedimento e o calibre do cateter puncionado e o nome do profissional que puncionou $[2,13]$.

Em geral, as complicações estão relacionadas a erros de execução e manutenção do cuidado e podem ser evitadas, observando-se os princípios básicos de assepsia, higiene hospitalar e realização adequada do procedimento [13], sendo que os fatores de risco podem ser: infecções, acidentes ocupacionais, perda ou a não manutenção das punçóes $[1,2,6,8,13,14]$.

Para garantir o sucesso da operaçáo, ao selecionar um local de punção devem ser considerados fatores como habilidade prática, material disponível, características do paciente (idade, estado físico e mental, se é destro ou canhoto e como reagem ao tratamento) e características da veia em si (firmeza, elasticidade, se palpável e visível) $[3,8,9,13]$.

$\mathrm{O}$ uso de curativos em cateteres venosos periféricos tem como finalidade a prevençáo das complicaçóes já referidas, podem reduzir contaminaçóes extrínsecas e o trauma no local de inserção do cateter, devendo mantê-lo limpo e seco, permitindo observação continua para identificaçáo precoce de complicaçóes locais da terapia intravenosa $[2,12,14]$.

Por outro lado, a segurança do profissional enfermeiro também é muito relevante no que diz respeito à punção venosa, já que o acesso vascular periférico e a administração de medicamentos são os procedimentos que implicam em maior risco de exposição ao sangue, realizados pela equipe de enfermagem [16,17]. Sendo assim, nunca se deve puncionar sem luvas, a fim de evitar o risco de acidentes ocupacionais [13].

Os valores das atividades educativas e da capacitação dos enfermeiros, periodicamente, constituem a linha mestra para a formação de uma equipe de saúde, crítica e consciente do seu papel de prevenção e controle das complicaçóes associadas aos procedimentos invasivos [1]. Devido a sua importância e abrangência, os profissionais devem implementar cuidados qualificados ao paciente e aprimorar esta área do conhecimento [5,9].

O que nos motivou na realização do presente estudo foi que durante as aulas teóricas, nossos companheiros de graduação de enfermagem apresentaram facilidade em aprender a técnica correta da PVP. Porém, no período que se refere às aulas práticas seguido assim dos estágios curriculares supervisionados, observamos as dificuldades vivenciadas pelos mesmos mediante o procedimento, tendo como consequência a má qualidade da assistência ao paciente, uma vez que, assim como a teoria, a prática também é de suma importância para o futuro profissional do acadêmico.

Considera-se que os dados encontrados podem servir de subsídios para futuras investigaçóes sobre o nível de conhecimento e desempenho dos acadêmicos de enfermagem quanto à técnica correta da punção venosa periférica e que os mesmos e também os profissionais de enfermagem possam aperfeiçoar a técnica evitando riscos de infecção e a insatisfação do paciente, diminuindo acidentes de trabalho e contribuindo para a reduçáo de gastos desnecessários de materiais na instituição, como dispositivos para infusão, algodão, álcool e esparadrapo. 
Desta forma, a pesquisa tem como objetivo: avaliar o nível de conhecimento e desempenho dos acadêmicos do sexto e oitavo período matriculados no curso de graduação em enfermagem no momento da punção venosa periférica em situação real de assistência, conhecer as dificuldades dos acadêmicos de graduaçáo em enfermagem na realização da punção venosa periférica e evidenciar qual dos períodos investigados assimilou melhor os conteúdos de punçáo venosa periférica oferecidos na disciplina Semiologia e Semiotécnica I.

\section{Material e métodos}

\section{Tipo de estudo}

Trata-se de um estudo cuja abordagem é exploratória do tipo transversal.

\section{Cenário do estudo}

A pesquisa teve como cenários três instituiçóes de saúde: Hospital São Vicente de Paulo, Hospital São Januário e Hospital Santa Isabel, no município de Ubá/MG. O contato inicial ocorreu por meio de um ofício no qual foram apresentados os objetivos do estudo e solicitada à autorizaçáo para a realizaçáo do mesmo através do termo de compromisso assinado pelos responsáveis pelas instituiçóes.

\section{Características da amostra}

De acordo com os critérios de inclusão, participaram da pesquisa 30 alunos, entre 20 e 40 anos de idade, do sexo masculino e feminino, cursando sexto e oitavo período do curso de graduação em Enfermagem, da Fundaçáo Presidente Antônio Carlos - Campos II, na cidade de Ubá. Realizaram aulas práticas no Hospital São Vicente de Paulo, Hospital Santa Isabel ou Hospital Sáo Januário e foram aprovados na disciplina de Semiologia e Semiotécnica I, disciplina esta que capacita e treina alunos para a realização da técnica da punção venosa periférica. Como critério de exclusão, alunos com idade inferior a 20 anos e superior a 40 anos, os quais estivessem matriculados no segundo e quarto períodos de Enfermagem.

A forma de obtenção da amostra foi intencional.

\section{Instrumentos}

Os instrumentos utilizados para a coleta de dados foram: um questionário elaborado pelos autores, respondido de forma anônima, contendo sete questóes, sendo seis de múltipla escolha e uma aberta, relativa a: idade, gênero, segurança na realização da técnica, complicaçóes, veias indicadas para acesso de longa permanência, centímetros quanto à colocaçáo do garrote e tipo de dispositivo indicado; também a observação direta através de um check list, segundo Torres et al. [1], constando os vinte e quatro passos para a execução da técnica da punção venosa periférica.

\section{Procedimentos}

Durante o mês de outubro de 2010, no primeiro momento, ocorreu a confecção do questionário. Para a realizaçáo da pesquisa foi elaborado um Termo de Consentimento Livre e Esclarecido (TCLE) de acordo com a resoluçáo 196/96 do Conselho Nacional de Saúde. Os alunos foram informados da pesquisa após a observaçáo direta da prática da PVP e orientados sobre os objetivos do estudo, a garantia do caráter confidencial e voluntário da pesquisa, bem como o compromisso de divulgaçáo dos resultados do trabalho. Após o referido termo foi assinado em duas vias, sendo uma de posse do participante.

O questionário foi no segundo momento aplicado aos alunos de graduação em Enfermagem pelos autores e acadêmicos do oitavo período do curso de graduação em Enfermagem da Fundação Presidente Antônio Carlos - Campos II, na cidade de Ubá; posteriormente houve a coleta dos dados pertinentes ao trabalho.

O trabalho foi encaminhado ao Comitê de Pesquisa da Fundação Presidente Antônio Carlos - FUPAC.

\section{Análise estatística}

A análise dos dados deu-se através da estatística descritiva com cálculo das médias, desvio padráo e porcentagem por meio do programa Excel.

\section{Resultados}

Dentre os 30 alunos que participaram do estudo, 15 eram do sexto período e 15 do oitavo período, com idade média de 25,33 anos e desvio padrão de 3,39 anos.

Os resultados revelaram diferenças estatísticas quanto ao nível de conhecimento e desempenho 
entre os períodos. Mediante o questionário aplicado aos alunos do sexto período, nota-se que 11 $(73,33 \%)$ sentem-se inseguros e apenas 4 (26,66\%) estão seguros para a realizaçáo da técnica da punçáo venosa periférica, 3 (20\%) alunos do oitavo período sentem-se inseguros e $12(80 \%)$ sentem-se seguros para realização de tal procedimento (Gráfico 1). Quanto ao tempo máximo do dispositivo de infusão de longa permanência recomendado pela Comissão de Controle de Infecção Hospitalar (CCIH), dentre os alunos do sexto período, evidencia-se que $5(33,33 \%)$ responderam 24 horas, $8(53,33 \%)$, 48 horas e apenas $2(13,33 \%)$ referem 72 horas. Já o oitavo período, 1 (6,66\%) optou por 12 horas, 2 (13,33\%), 24 horas, 4 (26,66\%), 48 horas e 8 $(53,33 \%)$ responderam que o tempo máximo é de 72 horas (Gráfico 2).

Gráfico 1 - Distribuição quanto à segurança na realização da punção venosa.

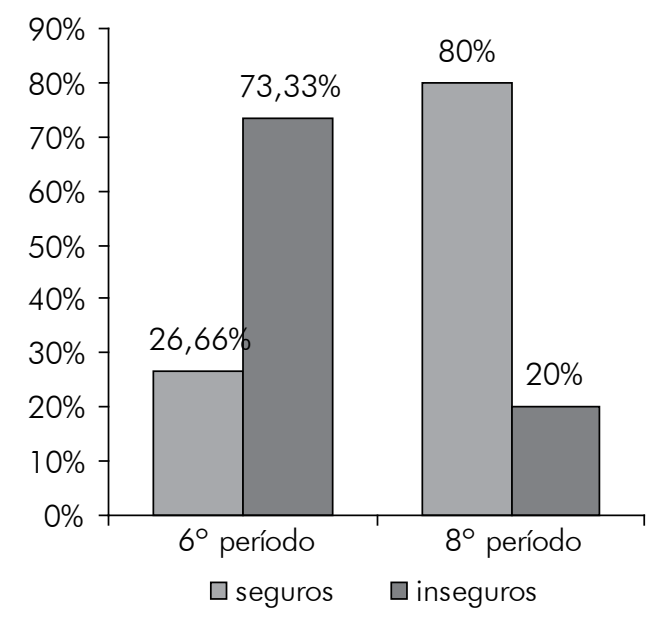

Gráfico 2 - Distribuição quanto ao tempo máximo do dispositivo de infusão de longa permanência recomendado pela $\mathrm{CCIH}$.

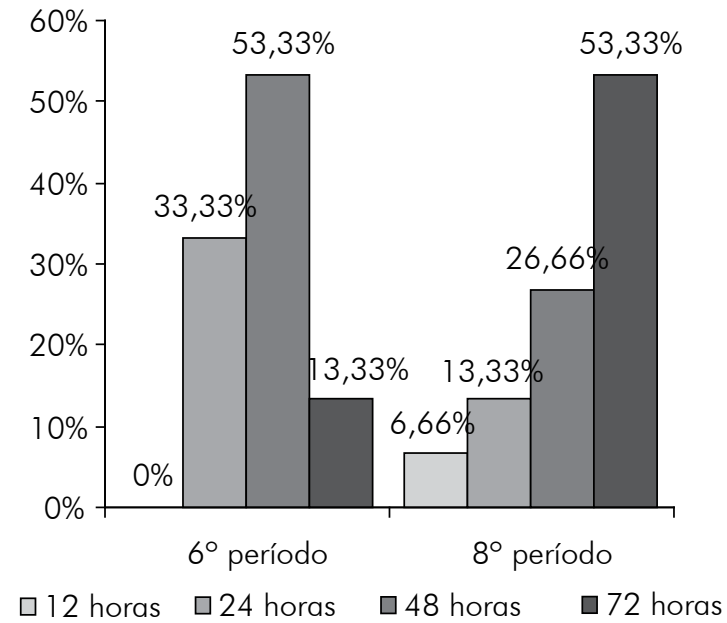

Em relação ao tipo de complicação mais provável quando o local de infusão apresenta-se frio, úmido e edemaciado ou doloroso, acadêmicos do sexto período mostraram-se bem divididos quanto a resposta correta distribuindo-se, em 3 (20\%) flebite, $5(33,33 \%)$ infiltraçáo, 3 (20\%) infecçáo local e 4 (26,66\%) hematoma. Em contrapartida, no oitavo período $3(20 \%)$ responderam flebite, 10 (66,66\%) infiltração, e apenas $2(13,33 \%)$ infecção local.

Gráfico 3 - Distribuição quanto à complicação mais provável quando o local da punção se apresenta frio, úmido e edemaciado ou doloroso.

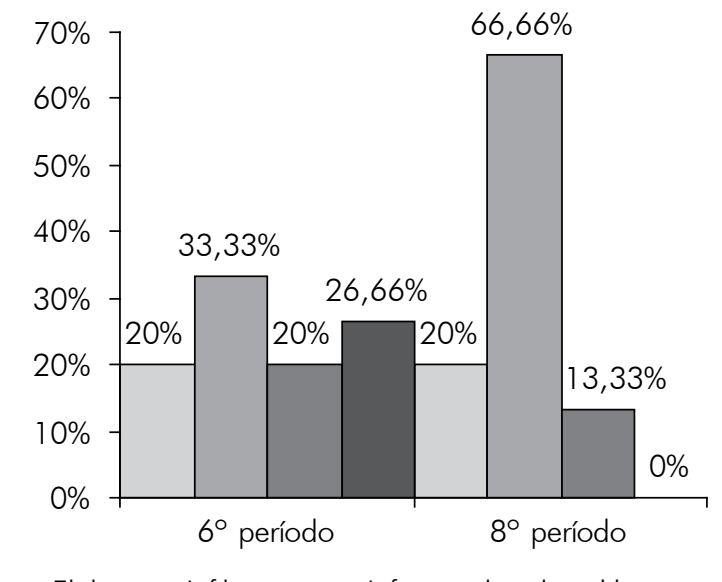

$\square$ Flebite $\square$ Infiltração $\square$ Infecção local $\square$ Hematoma

O Gráfico 4 mostra a distribuição dos alunos quanto ao dispositivo mais adequado para infusão venosa periférica de longa permanência, constatando entre os acadêmicos do sexto período, 10 (66,66\%) responderam cateter plástico, $4(26,66 \%)$ scalp e $1(6,66 \%)$ optou pelo intracath. O oitavo mostrou-se mais assertivo e $14(93,33 \%)$ responderam cateter plástico e apenas $1(6,66 \%)$ scalp.

Gráfico 4 - Distribuição quanto ao dispositivo ideal para infusão venosa periférica de longa permanência.

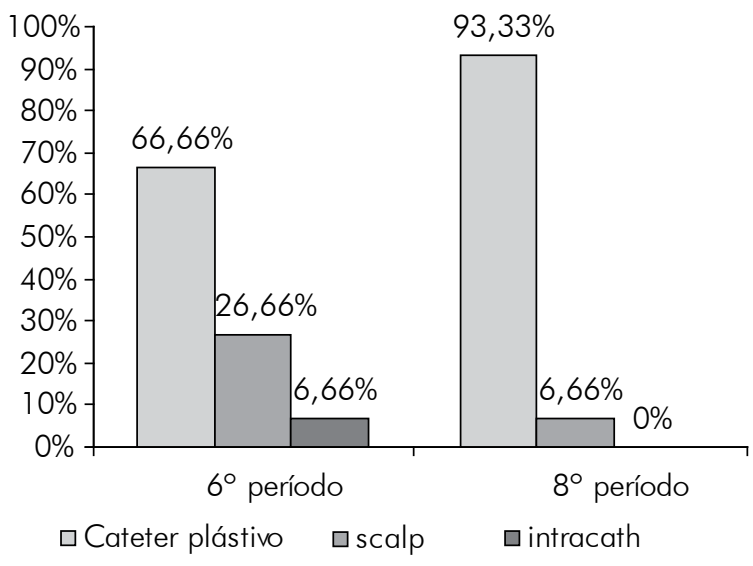


Quando questionados sobre as veias que não são indicadas para o acesso venoso de longa permanência, dentre o sexto período, 5 (33,33\%) assinalaram veias do braço, 7 (46,66\%) do dorso da máo e $3(20 \%)$ veias do ante-braço. Já os alunos do oitavo período, 3 (20\%) referem veias do braço, 7 $(46,66 \%)$ do dorso da mão e $5(33,33 \%)$ responderam que são as veias do ante-braço.

Ao analisarmos quantos centímetros do local da punção deve ser colocado o garrote, os alunos do sexto período mostraram uma margem de erro maior em relação ao oitavo apresentando tais resultados: nenhum escolheu a opção 2 e $12 \mathrm{~cm}$, $11(73,33 \%) 4 \mathrm{~cm}, 4(26,66 \%) 10 \mathrm{~cm}$ e dentre os alunos do oitavo período nenhum optou por $2 \mathrm{~cm}, 5(33,33 \%) 4 \mathrm{~cm}, 8(53,33 \%) 10 \mathrm{~cm}$ e 2 $(13,33 \%) 12 \mathrm{~cm}$.

Ao se perguntar sobre a conduta a ser realizada quando o local da punção apresentar sinais de complicaçóes, fica clara a vantagem para a retirada do acesso venoso na opiniáo de $12(80 \%)$ dos acadêmicos do sexto período, sendo que suspender a infusão também foi respondida por $1(6,66 \%)$ e $2(13,33)$ não souberam responder. Enquanto a maioria dos alunos do oitavo período (93,33\%) optaram por retirar o acesso e somente $1(6,66 \%)$ por fechar o dispositivo.

Os resultados da adesão aos passos da técnica da PVP, obtidos através da observação prática dos alunos, estão demonstrados na Tabela I e II. O item que diz respeito a checar a prescrição médica, apontou resultados insatisfatório para o sexto período, 8 $(53,33 \%)$ realizaram corretamente e 7 (46,66\%) não checaram a prescrição (Tabela I). Em contrapartida no oitavo período $100 \%$ dos alunos aderiram ao passo (Tabela II).

No que diz respeito à lavagem das mãos, a pesquisa demonstrou resultados significantes. $\mathrm{Na}$ observação do sexto período apenas 2 (13,33\%) realizaram corretamente, $9(60 \%)$ parcialmente e $4(26,66 \%)$ não realizaram (Tabela I). No oitavo período $2(13,33 \%)$ realizaram corretamente, 10 $(66,66 \%)$ realizaram parcialmente e $3(20 \%)$ náo realizaram a lavagem das mãos (Tabela II). Já no item que diz respeito a explicar o procedimento ao paciente, entre os acadêmicos do sexto período 2 $(13,33 \%)$ realizaram corretamente, 3 (20\%) parcialmente e 10 (66.66\%) não explicaram. Entre o

Tabela I - Frequência de adesão do sexto período aos passos da punção venosa periférica.

\begin{tabular}{|c|c|c|c|}
\hline Passos da técnica & $\begin{array}{c}\text { Realizou corre- } \\
\text { tamente }\end{array}$ & $\begin{array}{c}\text { Realizou par- } \\
\text { cialmente }\end{array}$ & Não realizou \\
\hline 1 - Verificar a prescrição médica & $53,33 \%(8)$ & $0,00 \%(0)$ & $46,66 \%(7)$ \\
\hline 2 - Lavar as mãos & $13,33 \%(2)$ & $60,00 \%(9)$ & $26,66 \%(4)$ \\
\hline 3 - Preparar o material & $80,00 \%(12)$ & $13,33 \%(2)$ & $6,66 \%(1)$ \\
\hline 4 - Explicar o procedimento ao paciente & $13,33 \%(2)$ & $20,00 \%(3)$ & $66,66 \%(10)$ \\
\hline 5 - Preparar o dispositivo intravenoso & $93,33 \%(14)$ & $6,66 \%(1)$ & $0,00 \%(0)$ \\
\hline 6 - Selecionar o local da punção venosa & $93,33 \%(14)$ & $6,66 \%(1)$ & $0,00 \%(0)$ \\
\hline 7 - Posicionar o membro no local da punção & $100 \%(15)$ & $0 \%(0)$ & $0 \%(0)$ \\
\hline 8 - Colocar o garrote a $10 \mathrm{~cm}$ de distanciamento local & $26,66 \%(4)$ & $20 \%(3)$ & $53,33(8)$ \\
\hline 9 - Calçar as luvas de procedimento & $100,00 \%(15)$ & $0,00 \%(0)$ & $0,00 \%(0)$ \\
\hline 10 - Manter o garrote & $100,00 \%(15)$ & $0,00 \%(0)$ & $0,00 \%(0)$ \\
\hline 11 - Fazer antissepsia com álcool 70\% & $93,33 \%(14)$ & $6,66 \%(1)$ & $0,00 \%(0)$ \\
\hline 12 - Esticar a pele no momento da punção & $73,33 \%(11)$ & $0,00 \%(0)$ & $26,66 \%(4)$ \\
\hline 13 - Inserir a agulha com bisel para cima & $100,00 \%(15)$ & $0,00 \%(0)$ & $0,00 \%(0)$ \\
\hline 14 - Observar o refluxo venoso & $93,33 \%(14)$ & $0,00 \%(0)$ & $6,66 \%(1)$ \\
\hline 15 - Soltar o garrote & $100,00 \%(15)$ & $0,00 \%(0)$ & $0,00 \%(0)$ \\
\hline 16 - Fechar o sistema & $100,00 \%(15)$ & $0,00 \%(0)$ & $0,00 \%(0)$ \\
\hline 17 - Fixar o dispositivo intravenoso & $80,00 \%(12)$ & $20,00 \%(3)$ & $0,00 \%(0)$ \\
\hline 18 - Infundir a solução & $93,33 \%(14)$ & $6,66 \%(1)$ & $0,00 \%(0)$ \\
\hline 19 - Observar as queixas e reações & $6,66 \%(1)$ & $13,33 \%(2)$ & $80,00 \%(12)$ \\
\hline 20 - Desprezar o material & $46,66 \%(7)$ & $13,33 \%(2)$ & $40,00 \%(6)$ \\
\hline 21 - Retirar as luvas e desprezá-las & $100,00 \%(15)$ & $0,00 \%(0)$ & $0,00 \%(0)$ \\
\hline 22 - Lavar as mãos & $26,66 \%(4)$ & $60,00 \%(9)$ & $13,33 \%(2)$ \\
\hline 23 - Orientar o paciente & $0,00 \%(0)$ & $0,00 \%(0)$ & $100,00 \%(15)$ \\
\hline 24 - Documentar o procedimento & $33,33 \%(5)$ & $0,00 \%(0)$ & $66,66 \%(10)$ \\
\hline
\end{tabular}


oitavo período $7(46,66 \%)$ realizaram corretamente, $1(6,66 \%)$ parcialmente e 7 (46,66\%) não explicaram o procedimento ao paciente.

Pode-se observar nos dados apresentados no item 9 da Tabela I, que 100\% dos alunos utilizaram luvas de forma correta, enquanto dos alunos do oitavo período $10(66,66 \%)$ utilizaram luvas e $5(33,33 \%)$ realizaram o procedimento sem calçar luvas.

Outro item investigado foi a antissepsia do local apresentada no item 11, onde a maior parte dos alunos do sexto período realizaram a técnica de forma correta sendo representados por $14(93,33 \%)$ e apenas $1(6,66 \%)$ realizou parcialmente. Os acadêmicos do oitavo período também tiveram uma margem de porcentagem significativa, $12(80 \%)$ realizaram corretamente e $3(20 \%)$ parcialmente .

Ao analisar o item 13, podemos observar que $100 \%$ dos alunos de ambos os períodos aderiram o passo da técnica corretamente.

Com relaçáo ao passo que se refere a observar o refluxo venoso, ambos os períodos mostraram desempenho excelente. Tanto o sexto quanto o oitavo realizaram corretamente de forma que representam $14(93,33 \%)$. Apenas 1 (6,66\%) do sexto período não realizou e para a mesma porcentagem o oitavo período realizou parcialmente .

Ao se tratar de observar as queixas e reaçóes do paciente, nenhum dos períodos do curso obtiveram resultado satisfatório, apenas 1 (6,66\%) dos alunos do sexto período aderiu ao passo, 2 (13,33\%) observaram parcialmente e $12(80 \%)$ não observaram. No oitavo período, $5(33,33 \%)$ realizam corretamente, $4(26,66 \%)$ parcialmente e $6(40 \%)$ não observaram as queixas e reaçóes do paciente.

Podemos observar que 7 (46,66\%) dos alunos do sexto período, desprezaram o material em local adequado, $2(13,33 \%)$ parcialmente e $6(40 \%)$ em local inadequado. Já o oitavo apresentou resultado satisfatório, sendo que 13 (86,66\%) desprezaram em local adequado e somente $2(13,33 \%)$ desprezaram parcialmente o material.

O item 23 também apresentou resultados significantes, sendo que nenhum dos alunos do sexto período orientou o paciente sobre os cuidados pós-punção. $\mathrm{O}$ oitavo período também apresentou resultado insatisfatório, já que apenas $2(13,33 \%)$ orientaram o paciente de forma correta, $3(20 \%)$ parcialmente e $10(66,66 \%)$ náo orientaram o paciente.

Tabela II - Frequência de adesão do oitavo período aos passos da punção venosa periférica.

\begin{tabular}{|c|c|c|c|}
\hline Passos da técnica & $\begin{array}{c}\text { Realizou corre- } \\
\text { tamente }\end{array}$ & $\begin{array}{c}\text { Realizou par- } \\
\text { cialmente }\end{array}$ & Não realizou \\
\hline 1 - Verificar a prescrição médica & $100,00 \%(15)$ & $0,00 \%(0)$ & $0,00 \%(0)$ \\
\hline 2 - Lavar as mãos & $13,33 \%(2)$ & $66,66 \%(10)$ & $20,00 \%(3)$ \\
\hline 3 - Preparar o material & $80,00 \%(12)$ & $13,33 \%(2)$ & $6,66 \%(1)$ \\
\hline 4 - Explicar o procedimento ao paciente & $46,66 \%(7)$ & $6,66 \%(1)$ & $46,66 \%(7)$ \\
\hline 5 - Preparar o dispositivo intravenoso & $93,33 \%(14)$ & $0,00 \%(0)$ & $6,66 \%(1)$ \\
\hline 6 - Selecionar o local da punção venosa & $93,33 \%(14)$ & $0,00 \%(0)$ & $6,66 \%(1)$ \\
\hline 7 - Posicionar o membro no local da punção & $100 \%(15)$ & $0 \%(0)$ & $0 \%(0)$ \\
\hline 8 - Colocar o garrote a $10 \mathrm{~cm}$ de distanciamento local & $33,33 \%(5)$ & $46,66 \%(7)$ & $20 \%(3)$ \\
\hline 9 - Calçar as luvas de procedimento & $66,66 \%(10)$ & $0,00 \%(0)$ & $33,33 \%(5)$ \\
\hline 10 - Manter o garrote & $100,00 \%(15)$ & $0,00 \%(0)$ & $0,00 \%(0)$ \\
\hline 11 - Fazer antissepsia com álcool 70\% & $80,00 \%(12)$ & $20,00 \%(3)$ & $0,00 \%(0)$ \\
\hline 12 - Esticar a pele no momento da punção & $86,66 \%(13)$ & $0,00 \%(0)$ & $13,33 \%(2)$ \\
\hline 13 - Inserir a agulha com bisel para cima & $100,00 \%(15)$ & $0,00 \%(0)$ & $0,00 \%(0)$ \\
\hline 14 - Observar o refluxo venoso & $93,33 \%(14)$ & $6,66 \%(1)$ & $0,00 \%(0)$ \\
\hline 15 - Soltar o garrote & $93,33 \%(14)$ & $0,00 \%(0)$ & $6,66 \%(1)$ \\
\hline 16 - Fechar o sistema & $93,33 \%(14)$ & $6,66 \%(1)$ & $0,00 \%(0)$ \\
\hline 17 - Fixar o dispositivo intravenoso & $93,33 \%(14)$ & $6,66 \%(1)$ & $0,00 \%(0)$ \\
\hline 18 - Infundir a solução & $93,33 \%(14)$ & $6,66 \%(1)$ & $0,00 \%(0)$ \\
\hline 19 - Observar as queixas e reações & $33,33 \%(5)$ & $26,66 \%(4)$ & $40,00 \%(6)$ \\
\hline 20 - Desprezar o material & $86,66 \%(13)$ & $13,33 \%(2)$ & $0,00 \%(0)$ \\
\hline 21 - Retirar as luvas e desprezá-las & $66,66 \%(10)$ & $0,00 \%(0)$ & $33,33 \%(5)$ \\
\hline 22 - Lavar as mãos & $13,33 \%(2)$ & $73,33 \%(11)$ & $13,33 \%(2)$ \\
\hline 23 - Orientar o paciente & $13,33 \%(2)$ & $20,00 \%(3)$ & $66,66 \%(10)$ \\
\hline 24 - Documentar o procedimento & $80 \%(12)$ & $13,33 \%(2)$ & $6,66 \%(1)$ \\
\hline
\end{tabular}


Outro item investigado foi a documentação do procedimento no prontuário, no sexto período, 5 $(33,33 \%)$ realizaram corretamente e $10(66,66 \%)$ deixaram de realizar, o que demonstra uma diferença bastante significativa quanto ao oitavo período no qual $13(86,66 \%)$ realizaram de forma correta, 2 $(13,33 \%)$ realizaram de forma parcial e apenas 1 $(6,66 \%)$ deixou de realizar.

Nos demais itens apresentados nas tabelas, ambos os períodos apresentaram resultados satisfatórios.

$\mathrm{Na}$ avaliação global do desempenho prático dos alunos obtidos através da observação direta da punção venosa, dentre os alunos do sexto período, 10,12 $(67,50 \%)$ realizaram corretamente, $1,54(10,27 \%)$ parcialmente e 3,33 ( $22,22 \%)$ não realizaram a técnica corretamente. Dentre os alunos do oitavo período, 10,95 $(73,05 \%)$ realizaram corretamente, $2,04(13,61 \%)$ parcialmente e $2(13,33 \%)$ náo realizaram a técnica corretamente (Gráfico 5).

Gráfico 5 - Desempenho global da realização da técnica de punção venosa periférica pelos alunos dos diferentes períodos.

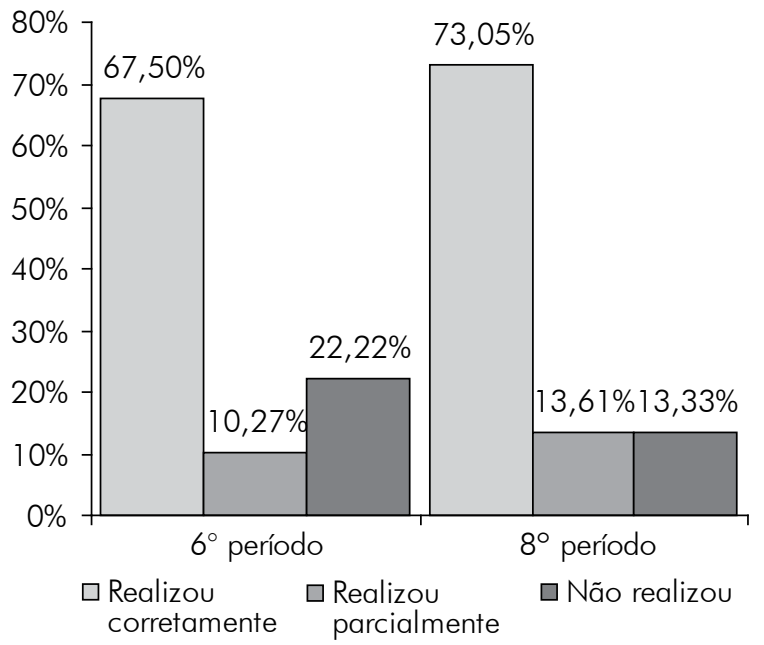

\section{Discussão}

$\mathrm{Na}$ análise do gráfico 1 foi possível identificar que os alunos do sexto período sentem-se inseguros na realização da técnica, entretanto, a maioria dos alunos do oitavo demonstraram-se seguros para a realizaçáo de tal procedimento. Este achado ainda não foi abordado por outros autores, porém parte desta amostra nega a hipótese do presente estudo de que ambos os períodos apresentariam insegurança para a realização da punção venosa.
Quando questionados em relação ao tempo máximo do dispositivo de longa permanência, a maioria dos alunos do sexto período optou por 48 horas, em contrapartida a maior parte dos alunos do oitavo período responderam que o tempo máximo é de 72 horas. Este resultado é semelhante ao de Pereira et al. [8], que realizaram um estudo relacionando o tempo de permanência in situ dos dispositivos venosos periféricos como cuidado de enfermagem, em 40 pacientes submetidos a procedimentos cirúrgicos, no Hospital das Clínicas de Ribeirão Preto da Universidade de Sáo Paulo, e verificaram que em $43 \%$ dos pacientes o dispositivo venoso permaneceu por um período menor que 24 horas; $36 \%$ de 24 a 48 horas e $11 \%$ de 48 a 72 horas, sendo que apenas $10 \%$ ficaram mais que 72 horas. Constatou-se que os dados obtidos relacionados ao tempo de permanência estão de acordo com o que traz a literatura e com o recomendado pela $\mathrm{CCIH}$, em que o tempo máximo do dispositivo não pode ultrapassar 72 horas.

Em relação ao gráfico 3, foi constatado que os acadêmicos do sexto período mostraram-se bem divididos entre hematoma e infiltração, mesmo sendo a segunda opção a mais prevalente; enquanto grande parte dos alunos do oitavo período responderam infiltração. Este resultado não foi demonstrado por outros autores, porém este estudo corrobora a literatura de Silva et al. [13], visto que a infiltraçáo é caracterizada por edema no local de inserção, dolorimento, pele fria e úmida, o que também foi demonstrado pela literatura de Potter \& Perry [2].

Quanto ao tipo de dispositivo utilizado para infusão de longa permanência, observamos que os acadêmicos do sexto e oitavo período, em sua maioria, relataram que o cateter plástico é o mais indicado para tal procedimento. Esses dados são semelhantes aos de Martins et al. [6], que verificaram a adesão às medidas assépticas para o acesso vascular em 6 hospitais de Goiânia - GO e a população constituiu-se de profissionais de enfermagem que atuam nas clínicas cirúrgicas e UTIs, evidenciando que o cateter venoso plástico permite manutenção por tempo mais prolongado.

Ao se tratar de lavagem das máos, dentre os diferentes períodos do curso, a maioria realizou de forma incorreta ou omitiu o passo. Este estudo é semelhante ao de Cirelli et al. [17], no qual foi avaliada a adesão às precauçóes padrão no acesso vascular periférico realizado em hospital geral privado de pequeno porte, onde se identificou que 
$84,4 \%$ das punçóes foram realizadas sem lavagem prévia das mãos. Segundo Torres et al. [1], que avaliaram o desempenho de 55 profissionais de enfermagem na execução da punção venosa periférica de um hospital geral de grande porte, a importância desse procedimento relaciona-se a falta de adesáo pelos trabalhadores da saúde e, concomitante, documentam inúmeras complicaçóes advindas dessa negligência. Já, Pedroso \& Magalhães [18] com o objetivo de identificar a frequência e o tempo despendido na realizaçáo dos procedimentos de punção venosa e sondagens, realizados em um hospital universitário de Porto Alegre - RS, constataram que a lavagem das máos foi observada em 100\% dos procedimentos. Ainda semelhante, Martins et al. [6] em seu estudo indicaram a não realizaçáo da lavagem das mãos por parte dos profissionais que deve preceder o cuidado.

No que diz respeito ao uso de luvas todos os alunos do sexto utilizaram de forma correta, já o oitavo período não obteve resultado tão satisfatório, uma vez que alguns realizaram a técnica sem a utilização de luvas. Esses dados diferem do estudo realizado por Martins et al. [6], em que verificou-se o uso de luvas de procedimento em 18 de 38 (47,4\%) oportunidades antes da inserção do cateter venoso periférico; e das 18 oportunidades de observaçáo de retirada do cateter, em apenas $10(58,8 \%)$ os profissionais a utilizaram.

Na realização da antissepsia com álcool a 70\%, pode observar-se que todos os alunos, do sexto e oitavo período, aderiram ao passo, porém uma pequena parte da amostra realizou parcialmente essa etapa do procedimento. Este estudo corrobora o de Martins et al. [6] , no qual foi verificado que em todas as punçóes periféricas foi realizada a antissepsia da pele com álcool a 70\% antes da introdução do cateter; porém não foi observada a limpeza prévia em presença de sujidade para antissepsia; a fricção por 30 segundos só foi observada em 19/38 (50\%) dos procedimentos.

Para análise do desempenho global da técnica da PVP, obtivemos resultados semelhantes ao estudo de Torres et al. [1], cujos dados apontam que os profissionais de enfermagem estáo desempenhando o procedimento de punçáo venosa periférica com percentuais de acertos e erros semelhantes, obtendo mediana global de acertos de 78\%. Embora o percentual de acertos seja significante, faz-se necessário analisar e intervir nos 22\% de erros. Ainda semelhante, Peduzzi et al. [19] demonstraram que em ambas as fases de observação direta os profissionais de nível médio mantêm um desempenho satisfatório, pois a primeira fase mostra variação de $87 \%$ a $84 \%$, e a segunda de $80 \%$ a $71 \%$.

Nos itens 4, 19 e 23 o desempenho mostra-se comprometido dentre os diferentes períodos. Os dados apresentados assemelham-se aos de Peduzzi et al. [19] cujo objetivo foi avaliar a qualidade da assistência de enfermagem prestada nas técnicas, no contexto da qualificação profissional de trabalhadores de enfermagem de nível médio, realizado em duas fases de observação, em 3 serviços hospitalares no estado da Bahia, e os achados mostram deficiência por parte da equipe de enfermagem na comunicaçáo com o paciente. Os resultados obtidos por Torres et al. [1] sustentam essa mesma concepção, demonstrando desempenho parcialmente satisfatório para os auxiliares de enfermagem (mediana de $100 \%$, percentil $25=33$ ) e para demais categorias, enfermeiro e técnico, desempenho insatisfatório.

A adesão ao passo que diz respeito à documentação do procedimento no prontuário, uma porcentagem significativa dos alunos do sexto período mostrou desempenho inadequado, enquanto a maioria dos acadêmicos do oitavo fez o registro corretamente após o procedimento. Parte deste estudo assemelha ao de Silva et al. [13], que menciona em sua literatura a importância em registrar no prontuário e na prescrição do cliente, a data e hora da instalação da venóclise, bem como o membro e o local deste onde ela foi efetuada, e que tipo de material foi utilizado, além das reaçóes apresentadas por todos os pacientes.

Foi notado também que durante a observaçáo prática dos alunos do sexto período a maioria apresentou dúvidas e foi orientado pelo supervisor de estágio.

\section{Conclusão}

Foi possível concluir através dos dados obtidos que os alunos do oitavo período assimilaram melhor o conteúdo da matéria de Semiologia e Semiotécnica I, visto que apresentaram o maior percentual de acertos e que os do sexto período apresentaram maior insegurança na realização da punção venosa periférica. Entretanto, observou-se que os alunos de ambos os períodos obtiveram desempenho satisfatório e erros semelhantes no desempenho técnico, relacionados à negligência de medidas que visam 
diminuir os riscos de infecção e na comunicação com o paciente.

É importante ressaltar que as dificuldades encontradas pelos alunos do sexto período podem ter sido influenciadas devido à mudança de professores da referida matéria que houve durante o curso, considerando que, os educadores tivessem formas diferentes para ensinar o conteúdo teórico e prático.

Acredita-se que outras pesquisas são necessárias de forma a auxiliar os graduandos do curso de enfermagem, e que os mesmos possam saber a importância em se aplicar a técnica corretamente. Além disso, cada vez mais deve ser implementado ao curso de graduação um constante aperfeiçoamento dos alunos no que se diz respeito à punção venosa periférica, visto que é um procedimento rotineiro para um profissional de enfermagem.

\section{Referências}

1. Torres MM, Andrade D, Santos CB. Punção Venosa Periférica: Avaliação de Desempenho dos Profissionais de Enfermagem. Rev Latinoam Enfermagem 2005;13(3):299-304.

2. Potter PA, Perry, AG. Grande Tratado de Enfermagem Prática Clínica e Prática Hospitalar. $3^{\circ}$ ed. São Paulo: Santos;1988. p.821-962.

3. Oliveira, FT, Silva, LD. Uso da solução salina para manutençáo de acessos venosos em adultos: uma revisão. Rev Bras Enfermagem 2006;59(6):787-90.

4. Flato UAP, Petisco GM, Santos FB. Punçáo venosa guiada por ultra-som em unidade de terapia intensiva. Rev Bras Ter Intensiva 2009;21(2):190-6.

5. Pedreira, MLG, Peterlini, MAS, Pettengill, MAM. Ultra-sonografia na punção intravenosa periférica: inovando a prática de enfermagem para promover a segurança do paciente. Acta Paul Enferm 2008;21(4):667-9.

6. Martins KA, Tiplle AFV, Souza ACSS, Barreto RASS, Siqueira KM, Barbosa JM. Adesão às medidas de prevenção e controle de infecção de acesso vascular periférico pelos profissionais da equipe de enfermagem. Cienc Cuid Saúde 2008;7(4):485-92.

7. Reis PED, Rodrigues CC, Vasques C, Carvalho EC. Efeitos adversos identificados em local de infusão intravenosa periférica por drogas quimioterápicas. Ciênc Enferm 2008;14(2):55-64.
8. Pereira RCC, Zanetti ML, Ribeiro KP. Tempo de permanência do dispositivo venoso periférico, in situ, relacionado ao cuidado de enfermagem em pacientes hospitalizados. Medicina (Ribeirão Preto) 2001;34:7984

9. Correia HAO, Ribeiro CA, Borba RIH. Realizando punção venosa ou arterial: significado para a equipe de enfermagem da UTI Pediátrica. Rev Gaúch Enferm 2009;30(3):558-60.

10. Silva APSS, Cogo ALP. Aprendizagem de punção venosa com objeto educacional digital no curso de graduaçáo em enfermagem. Rev Gaúch Enferm 2007;28(2):187-92.

11. Tardivo TB, Neto JF, Júnior JF. Infecçôes sanguíneas relacionadas aos cateteres venosos. Rev Bras Clin Med 2008;(6):224-27.

12. Silva MT, Silva SRP. Manual de procedimentos para estágio em enfermagem. São Paulo: Martinari; 2006. p. 113-20.

13. Silva MF, Souza NVD, Pereira SEM. Empregados procedimentos de enfermagem no déficit nutricional e hidroeletrolítico. In: Silva LD, Pereira SEM, Mesquita AMF. Procedimentos de Enfermagem: Semiotécnica para o Cuidado. Rio de Janeiro: Guanabara Koogan; 2004. p.199-230.

14. Machado AF, Pedreira MLG, Chaud MN. Estudo prospectivo, randomizado e controlado sobre o tempo de permanência de cateteres venosos periféricos em crianças, segundo três tipos de curativos. Rev Latinoam Enfermagem 2005;13(3):291-8.

15. Rodrigues ZS, Chaves EMC, Cardoso MVLML. Atuação do enfermeiro no cuidado com o cateter central de inserção periférica no recém nascido. Rev Bras Enferm 2006;59(5):626-9.

16. Fonseca EFR, Christoffel MM, Rosa PAN. Açôes de enfermagem na punção venosa: minimizando a dor do recém- nascido. Revista de Pesquisa: Cuidado é fundamental Online 2010; 2(2):947-57.

17. Cirelli MA, Figueiredo RM, Zem-mascarenhas SH. Adesão às precauçóes padrão no acesso vascular periférico. Rev Latinoam Enfermagem 2007;15(3):512-4.

18. Pedroso AGS, Magalhães AMM. Análise da punção e sondagem nasogástrica e nasoenteral em unidade de internação pediátrica. Rev Gaúcha Enferm 2008;29(1):18-25.

19. Peduzzi M, Anselmil MA, Junior IF, Santos CB. Qualidade no desempenho de técnicas dos trabalhadores de enfermagem de nível médio. Rev Saúde Pública 2006;40(5):843-50. 